\title{
Low dielectric polyimide/poly(silsesquioxane)-like nanocomposite material
}

\author{
Mei-Hui Tsai, Wha-Tzong Whang* \\ Department of Materials Science and Engineering, National Chiao Tung University, Hsin Chu 300, Taiwan, ROC
}

Received 11 August 2000; received in revised form 26 October 2000; accepted 31 October 2000

\begin{abstract}
A new type of low dielectric polyimide/poly(silsesquioxane)-like (PI/PSSQ-like) hybrid nanocomposite material is successfully prepared from the polyimide (ODA-ODPA) precursor containing phenyltrialkoxysilane (PTS) at two chain ends and monoaryltrialkoxysilane with a self-catalyzed sol-gel process. We employ $p$-aminophenyltrimethoxysilane (APTS) to provide bonding between the PTS and ODPA-ODA phase. It is shown by transmission electron microscopy (TEM) and scanning electron microscopy (SEM) that the PSSQ-like domain sizes with uniform size are fairly well separated in the hybrid films. The silica domain sizes of 5000-PIS and 5000-PIS-50-PTS films are in the range of 30-100 nm, of 5000-PIS-100-PTS and 10000-PIS-100-PTS in the range of 80-200 and 300-600 nm, respectively. The dielectric constant can be 2.79 for 5000-PIS-140-PTS with fairly good mechanical properties. The PI/PSSQ-like hybrid films have higher onset decomposition temperature and char yield in thermogravimetric analysis (TGA) and higher $T_{\mathrm{g}}$ in differential scanning calorimetry (DSC) than the pure PI. Moreover, the PI/PSSQ-like hybrid films have excellent transparency even under high PTS content. In the series of $X$-PIS hybrid films, the coefficient of thermal expansion (CTE) below $T_{\mathrm{g}}$ increases with the PI block chain length, but in the series of $X$-PIS- $y$-PTS films, it slightly increases with the PTS content. However, above $T_{\mathrm{g}}$ the CTE of $X$-PIS and $X$-PIS-24-PTS is much lower than that of the pure PI. The dielectric constant and water absorption of $X$-PIS- $y$-PTS films decrease with the PTS content because of the higher free volume and hydrophobicity. (C) 2001 Elsevier Science Ltd. All rights reserved.
\end{abstract}

Keywords: PI/PSSQ-like; Nanocomposite; Low dielectric

\section{Introduction}

Polyimides have been widely utilized as packaging material and dielectric layers for the electronic and microelectronic industry because of their outstanding characteristics such as low dielectric constant [1-4]. Interlayer dielectrics of ULSI multilevel interconnections require a low dielectric constant because of many problems in circuit performance, such as signal transmission rates and power dissipation [5]. A low dielectric constant is one of the most attractive properties of polyimide materials for electronics applications. It was expected that a low dielectric constant could be achieved by having large substituted groups or perfluorgroups [6-11] in a molecular skeleton. The former would lead to a higher free volume content and the latter would reduce the polarization under an electric field. Introducing fluorine atoms into polyimides is one of the most popular ways of achieving this purpose. However, the fluoro-polyimides may have low adhesion strength, low

\footnotetext{
* Corresponding author. Tel.: +886-3-5731873; fax: +886-3-5724727.
}

E-mail address: wtwhang@cc.nctu.edu.tw (W.-T. Whang). glass transition temperature, low mechanical strength or high thermal expansion coefficient (CTE). Moreover, they are expensive.

Several studies have been carried out on the preparation of polyimide-silica [12-34] hybrid material with silica particles dispersed in the polyimide matrix. Iyoku et al. introduced methyltriethoxysilane (MTES) [32] and phenyltriethoxysilane (PhTES) [33] into the polyamic acid (ODAPMDA precursor). Furthermore, for polyimide (ODAPMDA) hybrids the MTES component was partially replaced with dimethyldiethoxysilane (DMDES) [34]. They are mostly produced by sol-gel technique, which can be viewed as a two-step network forming process, the first step being the hydrolysis of a metal alkoxide and the second consisting of a polycondensation reaction. The hybrids have been aimed directly at improving the properties of polyimide in terms of better mechanical strength and uniform nanocomposite. Nevertheless, there is little research focusing on dielectric properties [35]. The main reason is that the dielectric constant of the polyimide-silica increases with the loading content of silica (about $k=3.9$ ) [35]. Poly(silsesquioxane) (PSSQ) is an important low 

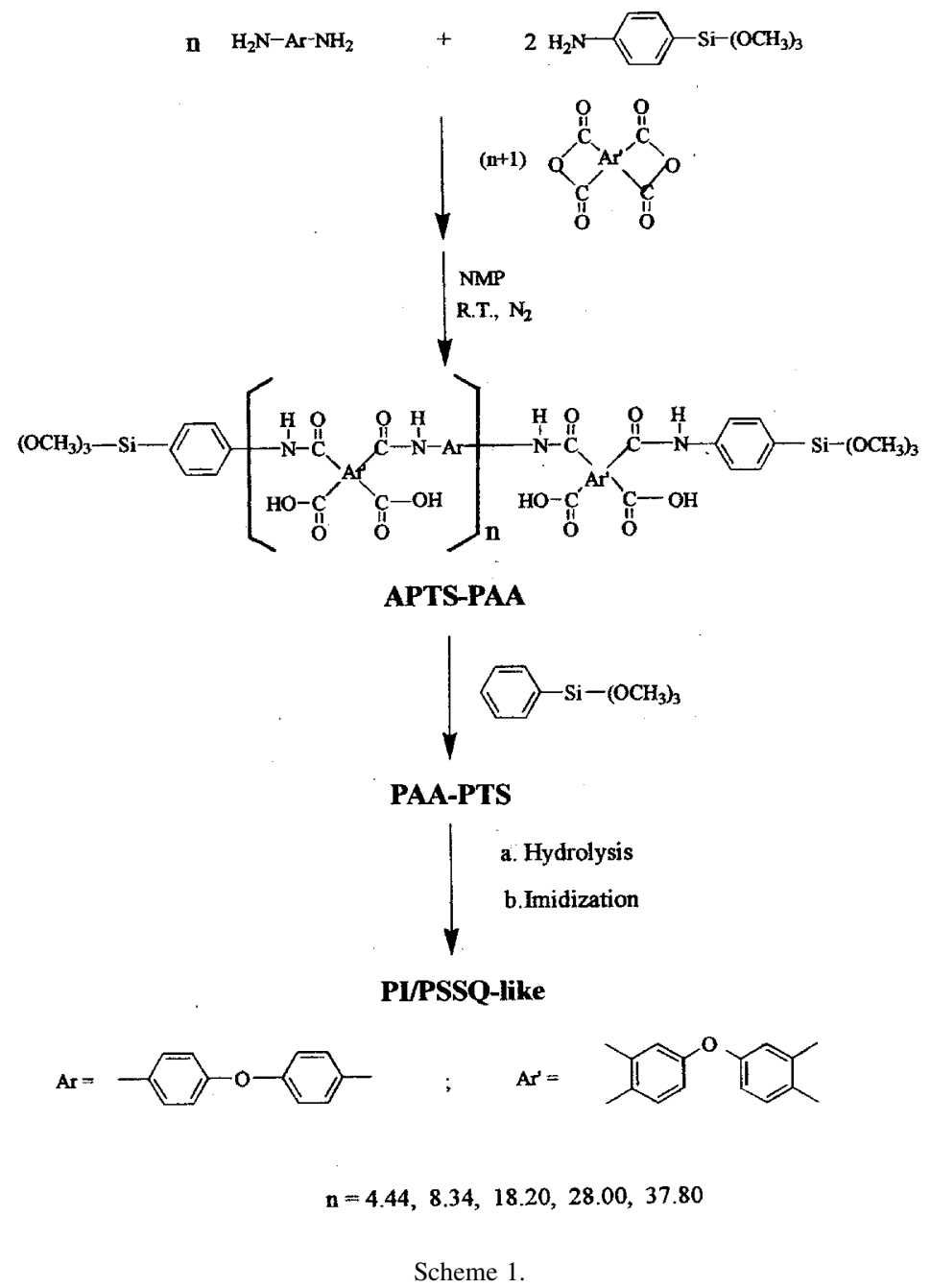

dielectric material in microelectronics [20,36,37]. The silica component based on phenyltrimethoxysilane (PTS), PSSQ-like with phenyl substitutes on the silicon atom, not only provides high thermal stability but also shows less volume contraction upon condensation than TMOS-based ones [20].

In this study, we intend to prepare low dielectric polyimide/PSSQ-like (PI/PSSQ-like) nanocomposite material by employing $p$-aminophenyltrimethoxysilane (APTS) to provide bonding between the PSSQ-like and polyimide ODA-ODPA phase through a sol-gel process. There are three unique features in the synthesis. First, it makes use of acid groups of PAA, rather than an additional acid or base, as the catalyst to carry out self-catalyzed condensation reaction. Second, the hydrolysis of methoxysilyl is processed by water from air and imidization of the polyamic acid APTSPAA or PAA-PTS. Third, the hybrid films can maintain excellent transparency even under high content of PTS and reasonable mechanical properties. Without adding catalyst, the hybrid films may maintain high clarity. Moreover, the synthesis method is simple and easy to apply to large-scale production. Although whether PAA is capable of self-catalyzing is still being disputed [28], it has been proved that adding acid or base and water creates larger silica domains and thus reduces the mechanical property of hybrid films $[28,31]$. This may reduce the transparency of the film.

Because the PI/PSSQ-like hybrid composite film is a new type of material, there are few systematic studies on its synthesis and characteristics to correlate with the chemical composition and physical structure. The dynamic mechanical properties of PI/PSSQ-like hybrid films have been discussed in our other paper [38]. In this article, we intend to correlate these properties with the silica component, the PSSQ-like content, the polyimide block chain length and the cross-linking density to understand the influence of composition of the low dielectric PI/PSSQ-like nanocomposites on their thermal stability, phase transitions, dielectric constants, CTE, moisture absorption, and optical transparency in the visible region. The morphology is also studied using a transmission electron microscope (TEM) and a scanning electron microscope (SEM). 


\section{Experimental}

\subsection{Materials}

4,4'-Diaminodiphenylether (ODA, 98\%) from Loncaster was dried in a vacuum oven at $120^{\circ} \mathrm{C}$ for $3 \mathrm{~h}$ prior to use. 3,3'-Oxydiphthalic anhydride (ODPA, 98\%) from Tokyo Chemical Industry was purified by recrystallization from acetic anhydride and then dried in a vacuum oven at $125^{\circ} \mathrm{C}$ overnight. $N$-methyl-2-pyrrolidone (NMP) from Tedia Company was dehydrated with molecular sieves. APTS (95\% para and 5\% meta) from Gelest Inc. and PTS (98\%) from Lancaster were used as supplied.

\subsection{Preparation of polymeric materials}

\subsubsection{Synthesis of aminophenyltrimethoxysilyl-terminated polyamic acid (APTS-PAA) oligomers}

The reaction is shown in Scheme 1. A three-neck flask $(250 \mathrm{ml})$ was first purged with nitrogen gas to remove the moisture prior to adding reagent. The polycondensation was carried out in the flask by adding a diamine ODA, a monoamine APTS, and a dianhydride in NMP under a nitrogen stream at room temperature. APTS was used to control the chain length of the trimethoxysilyl-terminated polyamic acid. In the preparation of the APTS-terminated PAA with a PAA block molecular weight of 5000, 0.04676 moles of ODPA was added into the solution containing 0.04176 moles of ODA and 0.01 moles of APTS in $75 \mathrm{~g}$ of NMP. ODPA was introduced into the solution in five portions. It is better to ensure the complete dissolution of the prior portion before adding a fresh portion. After the dissolution of all ODPA, the reaction mixture was further stirred for $2 \mathrm{~h}$ at room temperature. The PAA solution had $25 \%$ of solid content $(\mathrm{w} / \mathrm{w})$. Other APTS-PAAs with different PAA block length were also prepared by the same method. The mole ratios of ODPA/ODA/APTS are shown in Table 1.

\subsubsection{Preparation of PAA-PTS solution and PI/PSSQ-like hybrid films}

The APTS-PAA solution stated above was divided into several equal portions ( $20 \mathrm{~g}$ solution for each). Different weights of PTS were added to each portion to get PAAPTS solutions with different weight ratios of PTS to APTSPAA $(8,16,24,36,50,70,100,140 \mathrm{w} / \mathrm{w} \%)$. Stirring was continued at room temperature for $15 \mathrm{~h}$, to give a homogenous solution.

APTS-PAA and PAA-PTS solutions were cast on glass plates and then maintained at room temperature in air (relative humidity $\geqq 70 \%$ ) at least 40 min to absorb water for the sol-gel process in the trialkoxysilane units. The cast films were step-heated at $60,100,150,200$, and $300^{\circ} \mathrm{C}$, each for $1 \mathrm{~h}$. The thickness of PI/PSSQ-like films from APTS-PAA and PAA-PTS ranged from 30 to $50 \mu \mathrm{m}$. The reaction of APTS-PAA and PAA-PTS into PI/
Table 1

Preparation of pure ODA-ODPA polyamic acid and APTS-PAA oligomers (solid content of pure PAA and APTS-PAA was 25\%)

\begin{tabular}{lll}
\hline$X^{\mathrm{a}}$ & ODPA:ODA:APTS $^{\mathrm{b}}$ & Inherent viscosities $^{\mathrm{c}}$ \\
\hline 3000 & $2.72: 2.22: 1$ & 0.29 \\
5000 & $4.67: 4.17: 1$ & 0.41 \\
10000 & $9.60: 9.10: 1$ & 0.46 \\
15000 & $14.50: 14.0: 1$ & 0.51 \\
20000 & $19.40: 18.9: 1$ & 0.57 \\
Pure PAA & $1.00: 1.00: 0$ & 0.97 \\
\hline
\end{tabular}

${ }^{a}$ Theoretical molecular weight of APTS-terminated polyamic acid oligomers.

b Mole ratio.

c The inherent viscosity were determined at a concentration of $0.5 \mathrm{~g} / \mathrm{dl}$ of pure PAA and APTS-PAA in NMP at $25^{\circ} \mathrm{C}$.

PSSQ-like through hydrolysis and condensation is described in Scheme 1. The structures of PSSQ and PI/PSSQ-like films are shown in Scheme 2. The PI/PSSQ-like hybrid films from APTS-PAA and PAA-PTS films are encoded as $X$-PIS and $X$-PIS- $y$-PTS, respectively, where $X$ is the molecular weight of each polyimide block and $y$ is the weight ratio percentage of PTS to APTS-PAA.

\subsection{Characterization}

The inherent viscosities $\left(\eta_{\text {inh }}\right)$ of pure PAA and APTSPAA were determined at a concentration of $0.5 \mathrm{~g} / \mathrm{dl}$ in NMP thermostated at $25^{\circ} \mathrm{C}$ by an Ubbelohde viscometer with the flow time of pure NMP solvent greater than $120 \mathrm{~s}$. IR spectra were measured with a Nicolet PROTEGE-460 FTIR. The transparency of the hybrid films was measured with a Shimuza UV-160A spectrophotometer in the transparency mode. Using the visible wavelength at $638 \mathrm{~nm}$, and air as reference $(T \%=99.93)$. We detect the transparency of hybrid films with the same thickness of $40 \mu \mathrm{m}$.

The samples for TEM study were prepared by putting 5000-PIS and 5000-PIS-100-PTS films into epoxy capsules first and then curing the epoxy at $70^{\circ} \mathrm{C}$ for $24 \mathrm{~h}$ in a vacuum oven. The hybrid-imbedded epoxy was microtomed with Leica Ultracut Uct into 90-nm-thick slices in a direction normal to the plane of the films. Subsequently, a layer of carbon about $3 \mathrm{~nm}$ thick was deposited on the surface of each slice that was being placed on mesh 200 copper nets for TEM observation. The TEM study was carried out using JEOL-2000 FX with an acceleration voltage of $200 \mathrm{kV}$ in measurement. SEM study was carried out with a Hitachi S4500 focusing on the fractured surfaces of hybrid films, which was broken after cooling in liquid nitrogen, and vapor deposition of a thin gold film.

The dielectric constant was measured by the LCR meter at $1 \mathrm{MHz}$ frequency after coating gold on two surfaces $300 \AA$ thick and $1.5 \mathrm{~cm}$ diameter. The dielectric constant (k) can be calculated from the following formula $k=$ $C d / A \varepsilon_{0}$, where $C$ is the observed capacitance, $d$ the film thickness, $A$ the gold area, and $\varepsilon_{0}$ the free permittivity. 


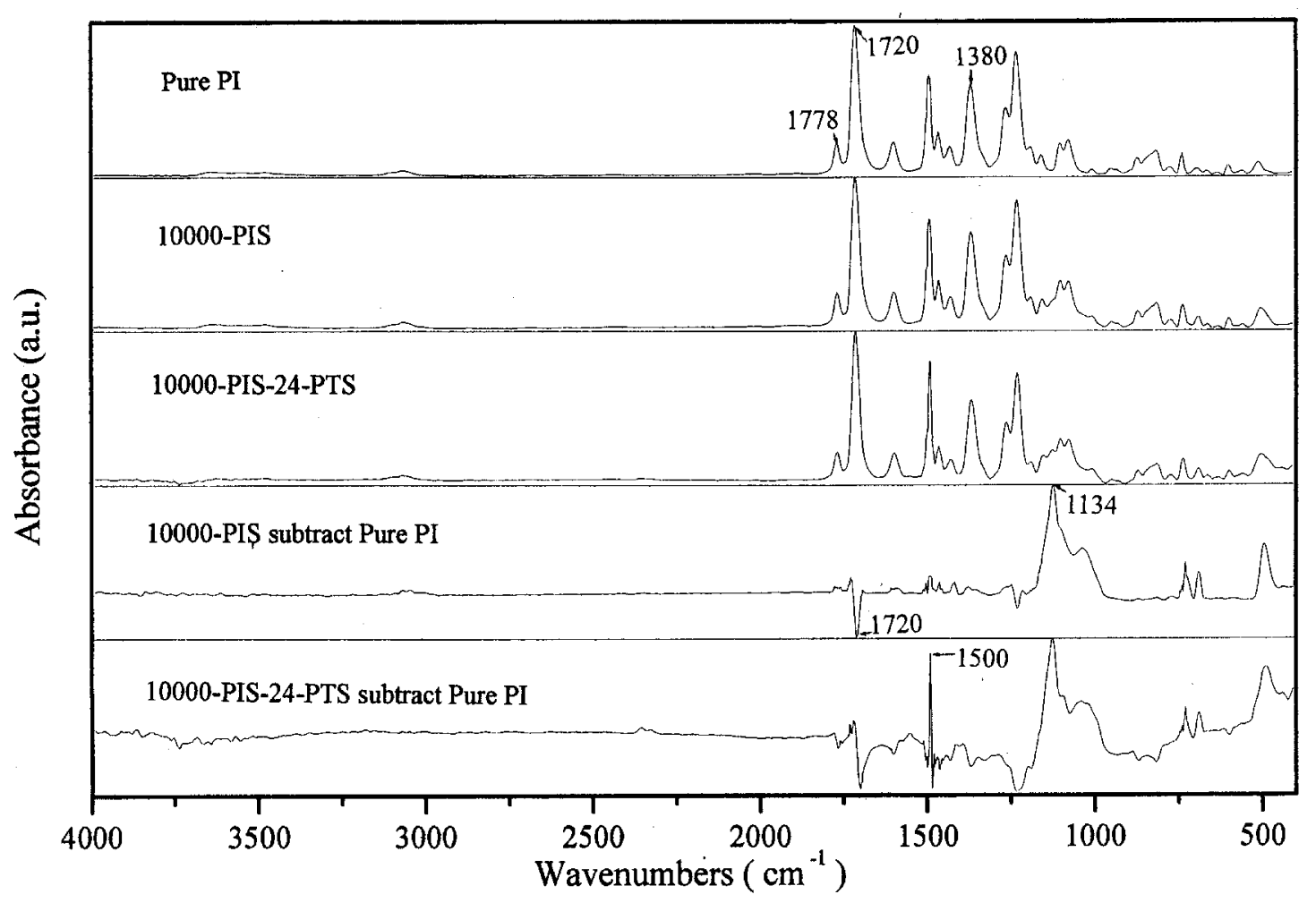

Fig. 1. Infrared spectra of pure PI, 10000-PIS and 10000-PIS-24-PTS and difference infrared spectra of 10000-PIS and 10000-PIS-24-PTS subtracting from that of pure PI.

Water absorption measurements were made with four pieces of the film (about $40 \mu \mathrm{m}$ thick), $3 \mathrm{~cm} \times 3 \mathrm{~cm}$ each. The hybrid films were first heated at $110^{\circ} \mathrm{C}$ for $1 \mathrm{~h}$ in a forced air convection oven to remove the water to get the initial weight of the film before soaking in water. The weight gains were measured as a function of soak time in distilled water at $23^{\circ} \mathrm{C}$ for $24 \mathrm{~h}$.

Thermogravimetric analysis (TGA) was carried out with a Du Pont Instruments 951 at a heating rate of $10^{\circ} \mathrm{C} \mathrm{min}{ }^{-1}$ under a nitrogen or air stream. The tested sample weighed about $10 \mathrm{mg}$. Differential scanning calorimeter (DSC) was carried out on a Du Pont Instruments 910 using a heating rate of $20^{\circ} \mathrm{C} \mathrm{min}^{-1}$. The in-plane thermal expansion (CTE) measurement was carried out in the range of $30-330^{\circ} \mathrm{C}$ by using a Du Pont 2940 probe, which provided $0.05 \mathrm{~N}$ tension force on the film, at a heating rate of $5^{\circ} \mathrm{C} \min ^{-1}$. The CTE values on the temperature scale between 30 to $220^{\circ} \mathrm{C}$ and $T_{\mathrm{g}}$ to $T_{\mathrm{g}}+50^{\circ} \mathrm{C}$ were recorded.

\section{Results and discussion}

\subsection{Synthesis characterization and morphology}

The PI/PSSQ-like hybrid films were obtained using the sol-gel process. The APTS-PAA oligomers were prepared by the reaction of $4,4^{\prime}$-diaminodiphenyl ether (ODA) with the $3,3^{\prime}$-oxydiphthalic anhydride (ODPA) in the presence of
APTS to control the polyimide block chain length $(X)$ ranging from 3000 to $20000 \mathrm{~g} \mathrm{~mole}^{-1}$ and end-group functionality. The inherent viscosities of APTS-PAA oligomers ranged from 0.29 to $0.57 \mathrm{dl} / \mathrm{g}$. The monomer composition and inherent viscosity of pure ODA-ODPA polyamide acid and APTS-PAA oligomers are shown in Table 1. It shows that the inherent viscosity increases with the PAA chain length. The hybrid films are obtained with a self-catalyzed hydrolysis/condensation (without adding other acid or base) by placing the cast APTS-PAA and PAA-PTS films at room temperature at least $40 \mathrm{~min}$ in atmosphere followed by step-heating to $300^{\circ} \mathrm{C}$ to form cross-linking networks of PI/PSSQ-like films. The first step is effected to absorb water and to cause the hydrolysis to proceed. Condensation mainly happens at the second step. Fig. 1 shows the infrared spectra of pure PI, 10000-PIS, and 10000-PIS-24-PTS and the difference infrared spectra of 10000-PIS and 10000PIS-24-PTS subtracting from pure PI. The asymmetric and symmetric carbonyl stretch of the imide ring at 1778 and $1720 \mathrm{~cm}^{-1}$ and the $\mathrm{C}-\mathrm{N}$ stretch at $1380 \mathrm{~cm}^{-1}$ are characteristic of the polyimide. The increase of the absorption band at $1110-1140 \mathrm{~cm}^{-1}$ in the difference spectra is due to $\mathrm{Si}-\mathrm{O}-\mathrm{Si}$ bond formation. The carbonyl peak at $1720 \mathrm{~cm}^{-1}$ may be from the symmetric carbonyl stretch of the imide ring and from the carbonyl stretch of the trace terminal dianhydrides. Therefore, 10000-PIS and 10000-PIS-24PTS has a slightly lower absorption at $1720 \mathrm{~cm}^{-1}$ than the pure PI. The increase absorption at $1500 \mathrm{~cm}^{-1}$ is due to the 

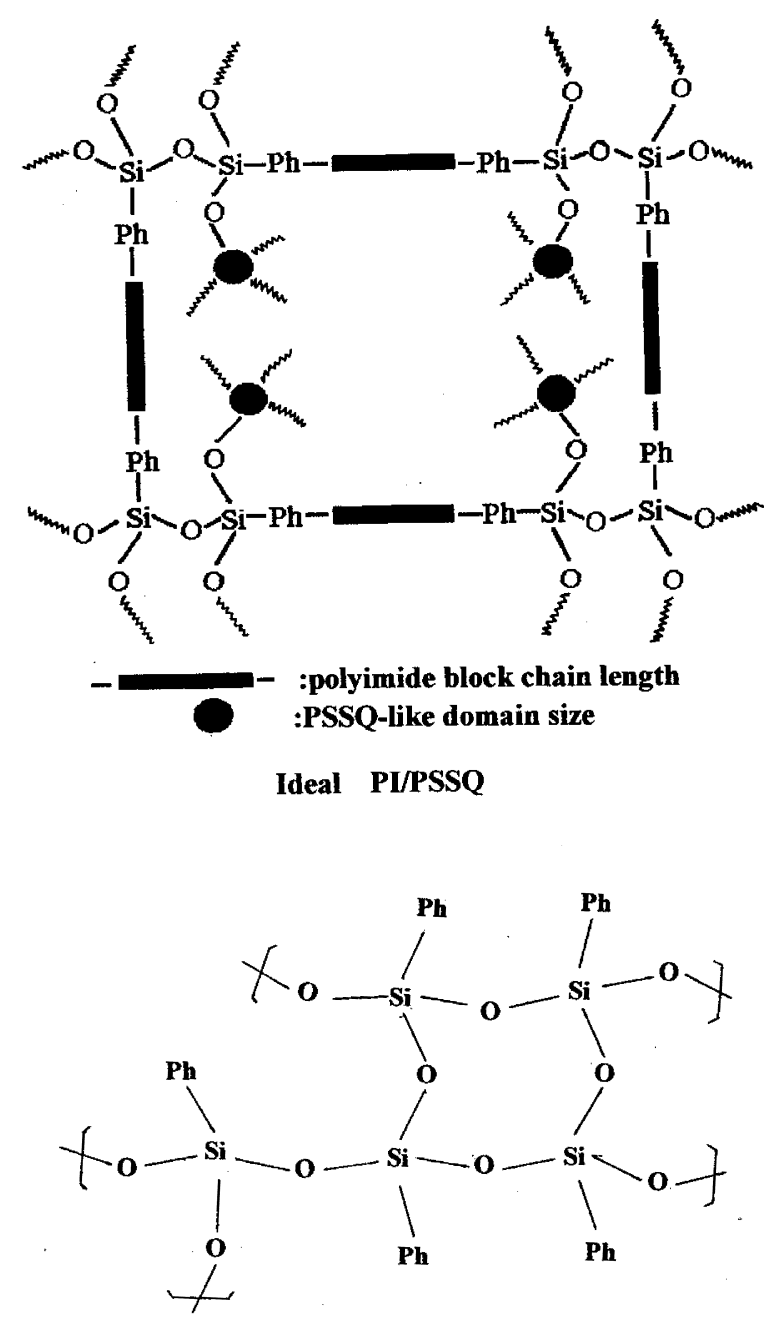

PSSQ-like

Scheme 2.

phenyl of the PSSQ-like domain. The $\mathrm{Si}-\mathrm{OH}$ or $\mathrm{Si}-\mathrm{OCH}_{3}$ stretching may show an infrared peak at $900-820 \mathrm{~cm}^{-1}$, but no such peak is found in the difference spectra. It may mean that the sol-gel process is well completed.

Ober and co-workers reported [31] that transparent hybrid formation required particular care in his synthesis. The metal alkoxides (TEOS or TMOS) and water needed to be added in small portions rather than one large potion to help retain solubility and avoid large-scale phase separation. Moreover, the acid catalyst favored self-condensation of the silica network, rather than condensation between the metal alkoxides and the PAA, and resulted in phase-separated, opaque films. Optical investigation of the transparent films indicated high homogeneity and a small silica domain. Our research has three features in synthesis. First, carboxylic acid groups of PAA, rather than additional acid or base, are used as catalysts to carry out self-catalyst hydrolysis/condensation reaction. Second, the water from the atmosphere is absorbed to hydrolyze trimethoxysilyl by
Table 2

Transparency characteristics of pure ODA-ODPA polyimide, 5000-PIS- $y$ PTS and 10000-PIS- $y$-PTS (thickness of films $=40 \mu \mathrm{m}$ )

\begin{tabular}{|c|c|c|c|c|c|c|}
\hline \multirow[t]{3}{*}{$y^{a}$} & \multicolumn{6}{|c|}{ Sample code } \\
\hline & \multicolumn{2}{|c|}{ Pure PI } & \multicolumn{2}{|c|}{ 5000-PIS-y-PTS } & \multicolumn{2}{|c|}{ 10000-PIS-y-PTS } \\
\hline & $T \%^{\mathrm{b}}$ & Opacity $^{\mathrm{c}}$ & $T \%$ & Opacity & $T \%$ & Opacity \\
\hline 0 & \multirow[t]{9}{*}{86.8} & \multirow[t]{9}{*}{-} & 87.1 & - & 87.6 & - \\
\hline 8 & & & 88.2 & - & 86.8 & - \\
\hline 16 & & & 87.7 & - & - & $-{ }^{\mathrm{d}}$ \\
\hline 24 & & & 87.9 & - & 87.8 & - \\
\hline 36 & & & 89.3 & - & 86.3 & - \\
\hline 50 & & & 87.6 & - & - & - \\
\hline 70 & & & 87.0 & - & 42.8 & + \\
\hline 100 & & & 70.9 & - & 30.3 & ++ \\
\hline 140 & & & 49.0 & + & - & - \\
\hline $\begin{array}{l}{ }^{\mathrm{a}} \mathrm{V} \\
\mathrm{b} \\
\mathrm{b} \\
\mathrm{c} \\
{ }^{\mathrm{c}} \mathrm{T} \\
{ }^{\circ}+ \\
{ }^{\mathrm{d}} \mathrm{N}\end{array}$ & $\begin{array}{l}\text { eight ra } \\
\text { ing vis } \\
\text { e opaci } \\
\text { slightly } \\
\text { t deter }\end{array}$ & $\begin{array}{l}\text { io }(\%) \text { of } \\
\text { ble light at } \\
\text { y was obse } \\
\text { cloudy; " } \\
\text { ained. }\end{array}$ & $\begin{array}{l}\text { TS to } A \\
638 \mathrm{~nm} \\
\text { ved wi } \\
+", \mathrm{cl}\end{array}$ & $\begin{array}{l}\text { S-PAAs. } \\
\text { d air as re } \\
\text { he naked }\end{array}$ & $\begin{array}{l}\text { nce. } \\
\text { as foll }\end{array}$ & “ - ", clear; \\
\hline
\end{tabular}

standing the cast PAA in air for at least $40 \mathrm{~min}$. Third, PTS needs to be added slowly to the APTS-PAA solution to ensure complete dissolution without precipitation. By this process, the hybrid films can maintain excellent transparency even under high content of PTS as shown in Table 2. Without adding catalyst it can attain high-purity hybrid films. The synthesis method is simple and easy to apply to large-scale production.

UV-VIS spectroscopy is used to measure the film transparency. Hybrid materials require high transparency in the visible range to facilitate their use as clear protective coatings. The transparencies of pure PI, 5000-PIS $-y$-PTS and 10000-PIS-y-PTS are shown in Table 2. The hybrid films of the 5000-PIS- $y$-PTS series are clear for the weight ratio of PTS/APTS-PAA, " $y$ ", $\leqq 100 \%$. The hybrid films become opaque when the " $y$ " value is $\geqq 140 \%$. The VIS-transmittance is $\geqq 87 \%$ when the " $y$ " value is $\leqq 70 \%$. On the other hand, the hybrid becomes opaque when the " $y$ " value is $\geqq 70 \%$ in 10000 -PIS- $y$-PTS films. The VIS-transmittance is $\geqq 86 \%$ when the " $y$ " value is $<50 \%$. The transparency of the PI/PSSQ-like films depends significantly upon the content of PTS and APTS. Table 2 shows that in the series of $X$-PIS- $y$-PTS films with a constant PI block length, the transparency decreases with the PTS content. This may be due to the increase of the PSSQ-like domain size with the PTS content, resulting in high scattering and leading to lower transparency. In comparison with 10000-PIS-yPTS, the corresponding 5000-PIS- $y$-PTS hybrid films with a shorter PI block chain length have a higher transparency at high PTS content. This may be due to the increase of the APTS content leading to a bigger silica domain and a smaller domain size as shown in Fig. 2 and high homogeneity in the hybrid films [14,24].

The transmission electron micrographs of the 5000-PIS 
(a)

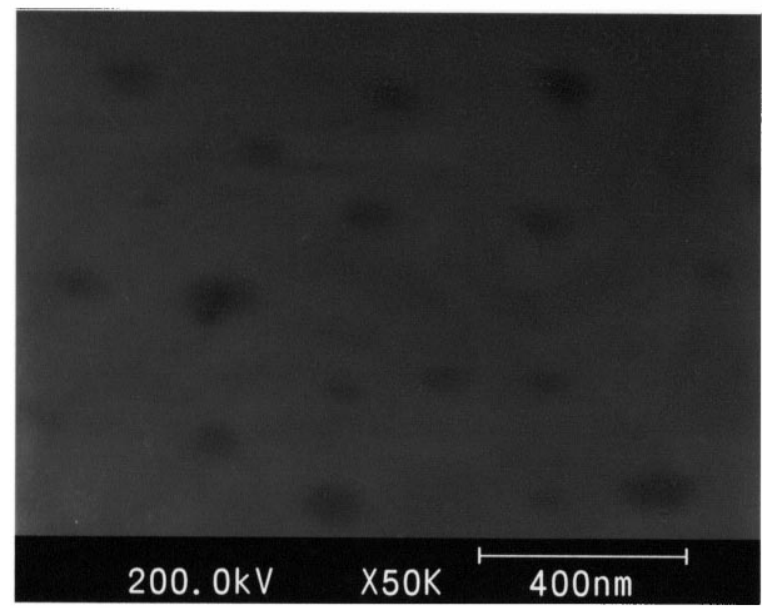

(b)

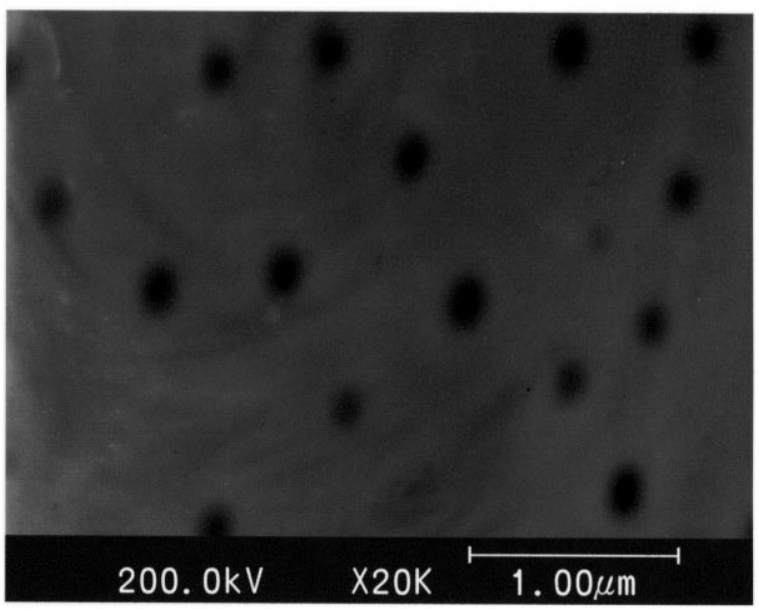

Fig. 2. Transmission electron micrographs of (a) 5000-PIS, and (b) 5000-PIS-100-PTS.

and 5000-PIS-100-PTS films are shown in Fig. 2(a) and (b). Inspecting Fig. 2(a), the TEM micrograph of 5000-PIS ambiguously displays PSSQ-like domains of $50-100 \mathrm{~nm}$ size homogeneously dispersed in PI. Fig. 2(b) shows the micrographs of the 5000-PIS-100-PTS film. The PSSQlike domain sizes $\leqq 200 \mathrm{~nm}$ are also homogeneously dispersed in the hybrid films even at high PTS content. The SEM micrographs in Fig. 3(a)-(d) show the fractured surface morphology of the hybrid films, which is broken after cooling in liquid nitrogen. The PSSQ-like domain sizes of $30-80 \mathrm{~nm}$ in the PI/PSSQ-like hybrid films are observed for both 5000-PIS and 5000-PTS-50-PTS and 80-200 and 300-600 $\mathrm{nm}$ for 5000-PIS-100-PTS and 10000-PIS-100-PTS, respectively. Apparently, in both 10000-PIS- $y$-PTS and 5000-PIS- $y$-PTS hybrid films, the domain size decreases with APTS content and increases with the PTS content in the hybrid films. On comparison of Figs. 3(c) and 2(b), the PSSQ-like domain sizes cannot be observed easily in the SEM photograph of 5000-PIS-100-
PTS, whereas they can be detected easily in the TEM photograph, which is more sensitive to the higher-atomic-number silicon. Both TEM and SEM micrographs reveal the same morphology of uniform distribution of PSSQ-like domains in the continuous PI phase and the domain size increases with the PTS content and PI block chain length.

\subsection{Dielectric constant and water absorption}

Dielectric constants of pure PI, 5000-PIS- $y$-PTS and 10000-PIS- $y$-PTS hybrid films with different PTS content are shown in Table 3 . The data shows that a higher $y$ value leads to the decrease in the dielectric constant. The trend is the same as that in density [35]. Both 5000-PIS-y-PTS and 10000-PIS $-y$-PTS films exhibit a similar trend: the more the PTS in the hybrid films, the lower the dielectric and density values. However, the dielectric constants of pure polyimide, 5000-PIS and 10000-PIS have relatively high values, 3.56 , 3.50 , and 3.61, respectively. These three dielectric constant

Table 3

Dielectric properties of pure ODA-ODPA polyimide, 5000-PIS- $y$-PTS and 10000-PIS- $y$-PTS

\begin{tabular}{|c|c|c|c|c|c|c|}
\hline \multirow[t]{3}{*}{$y$} & \multicolumn{6}{|l|}{ Sample code } \\
\hline & \multicolumn{2}{|l|}{ Pure PI } & \multicolumn{2}{|l|}{ 5000-PIS- $y$-PTS } & \multicolumn{2}{|l|}{ 10000-PIS-y-PTS } \\
\hline & Density $\left(\mathrm{g} / \mathrm{cm}^{3}\right)$ & $k^{\mathrm{a}}$ & Density $\left(\mathrm{g} / \mathrm{cm}^{3}\right)$ & $k$ & Density $\left(\mathrm{g} / \mathrm{cm}^{3}\right)$ & $k$ \\
\hline 0 & 1.3675 & 3.56 & 1.3641 & 3.50 & 1.3692 & 3.61 \\
\hline 36 & & & 1.3541 & 3.32 & 1.3516 & 3.38 \\
\hline 70 & & & 1.3350 & 2.89 & 1.3378 & 2.96 \\
\hline 100 & & & 1.3341 & 2.89 & 1.3198 & 2.85 \\
\hline 140 & & & 1.3144 & 2.79 & $-\mathrm{b}$ & - \\
\hline
\end{tabular}

\footnotetext{
${ }^{\text {a }}$ Dielectric constant measured by LCR meter at $1 \mathrm{MHz}$.

b Not determined.
} 
(a)

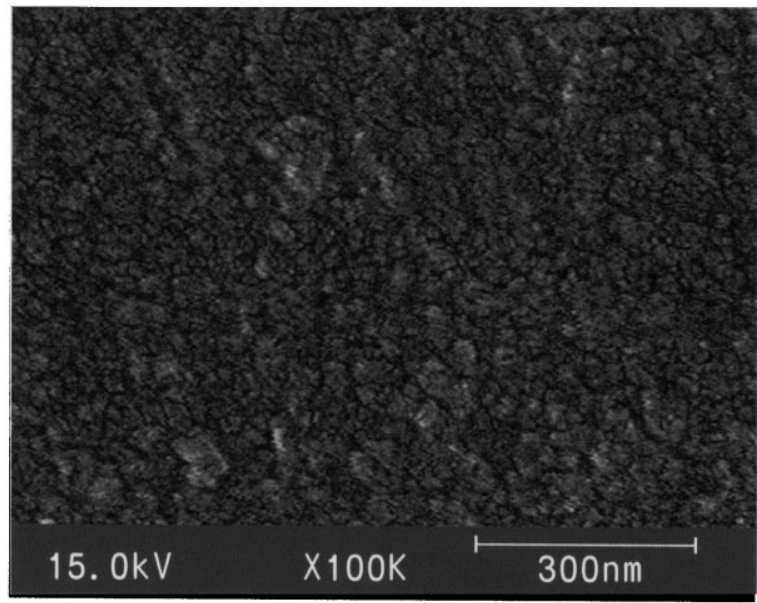

(c)

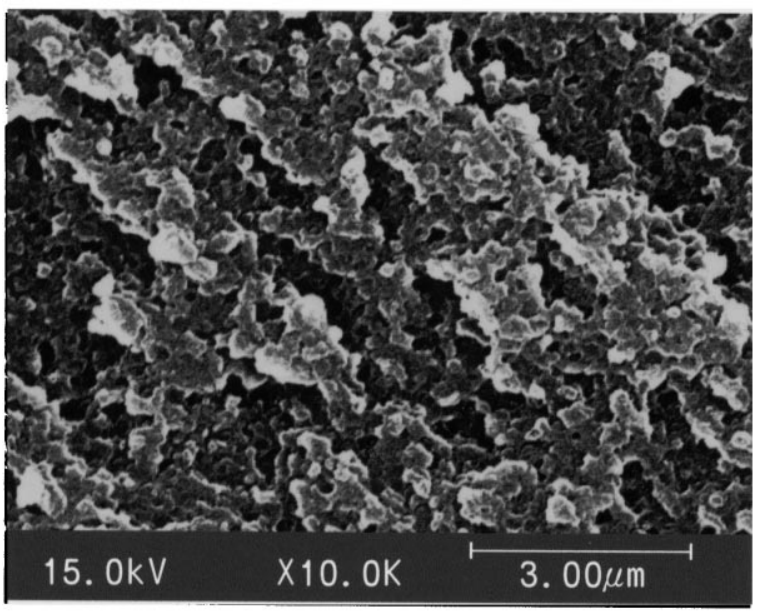

(b)

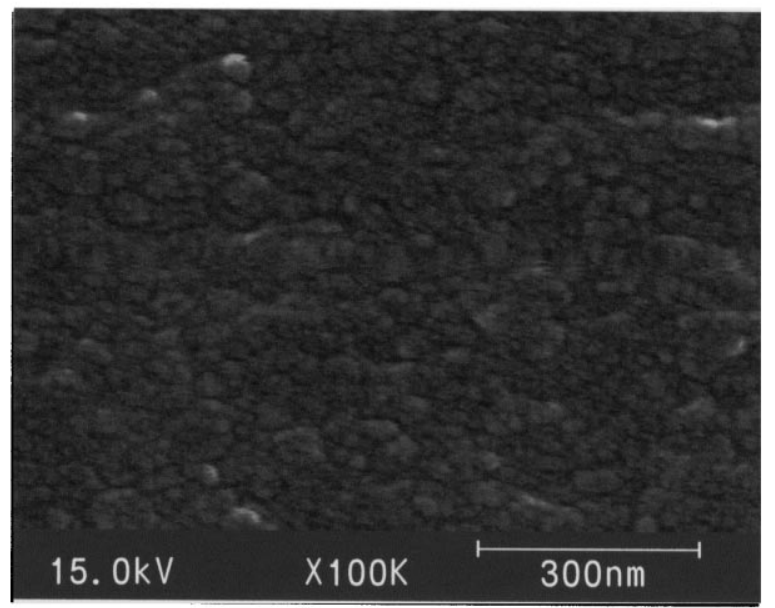

(d)

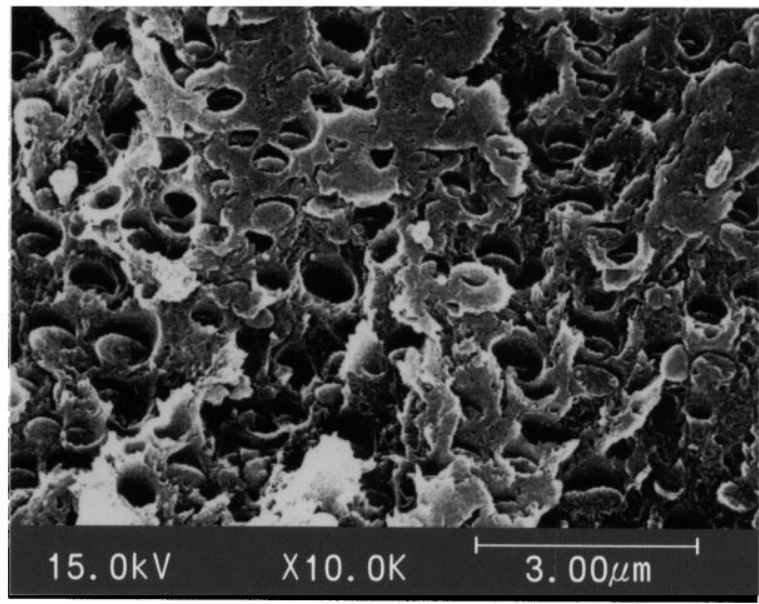

Fig. 3. Scanning electron micrographs of the fracture surfaces of (a) 5000-PIS, (b) 5000-PIS-50-PTS, (c) 5000-PIS-100-PTS, and (d) 10000-PIS-100-PTS.

values are also in accordance with the relative relationship of their density. The higher the density, the higher the dielectric constant in the polymer films. Higher PTS content can cause the formation of bigger PSSQ-like domains, which is like the nodes in the three-dimensional networks that bond PI blocks together. PI is a semi-rigid polymer. A bigger PSSQ-like domain may increase slightly the separation of the PI interblock and increase the free volume and decrease the density. Usually, free volume is easily occupied by small water molecules and increases the dielectric constant because of its high dielectric constant, 80. The PSSQ-like domains may exhibit some hydrophobicity. Therefore, the more free volume is created in the structure, the less the water uptake as shown in Table 4. Hence, introducing more PTS content in the hybrid film lowers the dielectric constant. The dielectric constants of the PI/
PSSQ-like films are affected by the free volume in the material and probably the hydrophobicity of the phenylPSSQ-like domain.

Water absorption of polymers heavily influences their dielectric constants and limits their application in the electric and microelectronic industry. It can increase the conductivity of the dielectric and promote the corrosion of metal conductors, which can potentially lead to device failure. Accordingly, it is important to develop polyimides having low water absorption. Water absorption of pure polyimide, 5000-PIS-y-PTS and 10000PIS- $y$-PTS hybrid films with different PTS content are shown in Table 4. The data indicate that pure polyimide, 5000-PIS, and 10000-PIS films have high water absorption (water uptake 1.1-1.2\%). Introducing PTS into the hybrid films significantly decreases the water 
Table 4

Water absorption of pure ODA-ODPA polyimide, 5000-PIS-y-PTS and 10000 -PIS- $y$-PTS (water absorption immerses in DI- $\mathrm{H}_{2} \mathrm{O}, 24 \mathrm{~h}$ at $23^{\circ} \mathrm{C}$, the data are the average of the three testing values)

\begin{tabular}{|c|c|c|c|}
\hline \multirow[t]{2}{*}{$y^{\mathrm{a}}$} & \multicolumn{3}{|c|}{ Sample code } \\
\hline & Pure PI & 5000-PIS-y-PTS & 10000-PIS-y-PTS \\
\hline 0 & 1.12 & 1.21 & 1.26 \\
\hline 8 & & 1.06 & 1.14 \\
\hline 16 & & 0.95 & $-{ }^{\mathrm{b}}$ \\
\hline 24 & & 0.85 & 1.09 \\
\hline 50 & & 0.76 & 0.84 \\
\hline 70 & & 0.67 & 0.69 \\
\hline 100 & & 0.70 & 0.60 \\
\hline 140 & & 0.46 & - \\
\hline
\end{tabular}

a Weight ratio (\%) of PTS to APTS-PAAs.

b Not determined.

absorption. The higher the PTS content the lower the water uptake in the hybrid film. PTS promotes the hydrophobicity of the PI/PSSQ-like hybrid films.

\subsection{Thermal characteristics}

The dynamic thermogravimetric curves of pure ODAODPA polymide, 1000-PIS-36-PTS, and 1000-PIS-100PTS films at a heating rate of $10^{\circ} \mathrm{C} \mathrm{min}^{-1}$ under nitrogen and air are shown in Fig. 4. The pure PI and 10000-PIS-yPTS films exhibit one-step decomposition. The former showed that the onset decomposition is at about $540^{\circ} \mathrm{C}$ under nitrogen and $500^{\circ} \mathrm{C}$ under air, respectively, but the latter starts at $590^{\circ} \mathrm{C}$ in nitrogen and $550^{\circ} \mathrm{C}$ in air. The PI/PSSQ-like films show excellent high thermal stability. They also have a higher char yield than the former at $800^{\circ} \mathrm{C}$.

The onset of the glass transition temperature of pure polyimide, $X$-PIS and $X$-PIS- $y$-PTS hybrid films are
Table 5

The onset of glass transition temperature of $X$-PIS and $X$-PIS-24-PTS hybrid films

\begin{tabular}{llll}
\hline$X^{\mathrm{a}}$ & \multicolumn{2}{c}{ DSC $T_{\mathrm{g}}\left({ }^{\circ} \mathrm{C}\right)^{\mathrm{b}}$} & \\
\cline { 2 - 4 } & Pure PI sample & $X$-PIS sample & $X$-PIS-24-PTS sample \\
\hline 3000 & & 267 & 265 \\
5000 & & 266 & 263 \\
10000 & & 264 & 263 \\
15000 & & 260 & 259 \\
20000 & & 258 & 257 \\
Pure PI & 255 & &
\end{tabular}

a Theoretical molecular weight of APTS-terminated polyamic acid oligomers.

$\mathrm{b}$ The onset glass transition temperature by DSC using a heating rate of $20^{\circ} \mathrm{C} \min ^{-1}$.

Table 6

The onset of glass transition temperature of pure polyimide and 5000-PIS$y$-PTS and 10000-PIS- $y$-PTS hybrid films

\begin{tabular}{rlc}
\hline$y^{\mathrm{a}}$ & \multicolumn{2}{c}{ DSC $T_{\mathrm{g}}\left({ }^{\circ} \mathrm{C}\right)^{\mathrm{b}}$} \\
\cline { 2 - 3 } & 5000 -PIS-y-PTS sample & 10000 -PIS- $y$-PTS sample \\
\hline 0 & 266 & 264 \\
8 & 265 & 264 \\
16 & 264 & $-{ }^{\mathrm{c}}$ \\
24 & 263 & 259 \\
36 & 263 & 260 \\
50 & 261 & - \\
70 & 259 & 260 \\
100 & 258 & 259 \\
140 & 256 & - \\
\hline
\end{tabular}

a Weight ratio (\%) of PTS to APTS-PAA.

b The onset glass transition temperature by DSC using a heating rate of $20^{\circ} \mathrm{C} \min ^{-1}$.

c Not determined.

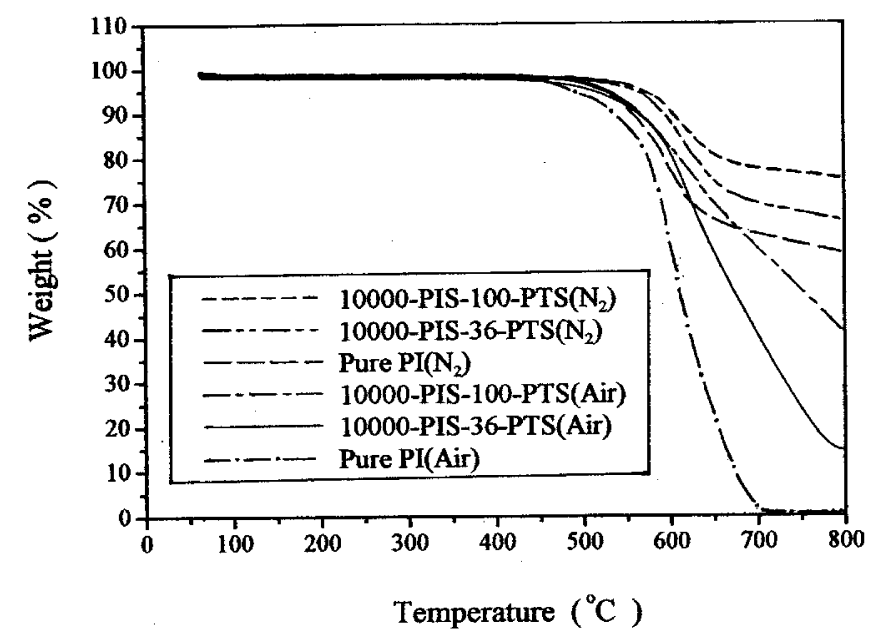

Fig. 4. Dynamic themogravimetric curves of pure polyimide and 10000-PIS-y-PTS. 


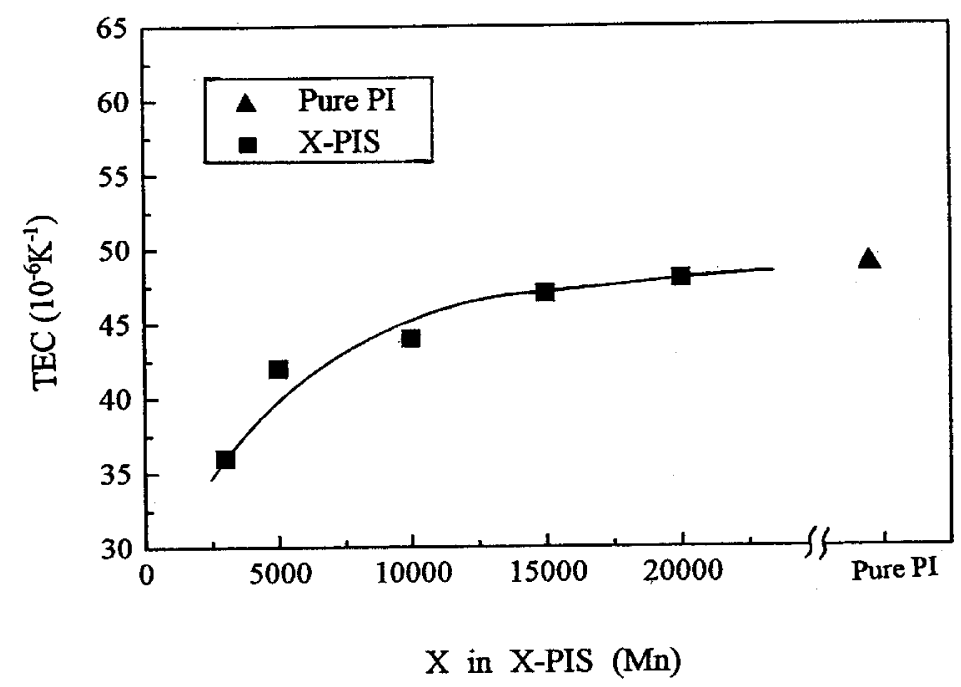

Fig. 5. Coefficient of thermal expansion below $T_{\mathrm{g}}\left(\alpha_{\mathrm{g}}\right.$, range $\left.30-220^{\circ} \mathrm{C}\right)$ of pure polyimide and $X$-PIS hybrid films.

shown in Tables 5 and 6. The data show that higher $y$ values and longer PI block chains lead to a decrease in the glass transition temperature. Although the $T_{\mathrm{g}}$ temperature decreases, it is still higher than that of the pure PI.

CTEs below $T_{\mathrm{g}}\left(\alpha_{\mathrm{g}}\right.$, range $\left.30-220^{\circ} \mathrm{C}\right)$ of pure polyimide and $X$-PIS hybrid films are shown in Fig. 5. It is observed that the $\alpha_{\mathrm{g}}$ decreases with increasing APTS content (shortening PI block length) in the hybrid films. Shortening the PI block length in the hybrid films increases the cross-linking density of the network structure, which results in increasing chain stiffness and $T_{\mathrm{g}}$, and therefore, decreases the $\alpha_{\mathrm{g}}$. Pure ODA-ODPA is a semi-rigid structure. Its molecular chain is more flexible than the hybrid films and has a higher $\alpha_{\mathrm{g}} . \alpha_{\mathrm{g}}$ of 5000-PIS-y-PTS hybrid films with different PTS content are shown in Fig. 6. With increasing PTS content, the $\alpha_{\mathrm{g}}$ slightly increases because the free volume increases and $T_{\mathrm{g}}$ decreases with the PTS content. CTEs above $T_{\mathrm{g}}\left(\alpha_{\mathrm{r}}\right.$, range $T_{\mathrm{g}}$ to $\mathrm{T}_{\mathrm{g}}+50^{\circ} \mathrm{C}$ ) of the $X$-PIS and $X$-PIS-24-PTS curves are shown in Fig. 7. It is worth noting that the $\alpha_{\mathrm{g}}$ of the $X$-PIS (Fig. 5) is slightly lower than that of the pure PI; however, the $\alpha_{\mathrm{r}} \mathrm{s}$ of $X$-PIS and $X$-PIS-24-PTS films decrease drastically compared with that of the pure PI. In particular, the decrease in $\alpha_{\mathrm{r}}$ is more significant for $X$-PIS-24-PTS films than the corresponding $X$-PIS films. It may be attributed, perhaps, to the greater PSSQ-like content. All the hybrid films have fairly good mechanical properties and have been discussed in our other article [38]. In $X$-PIS-y-PTS the tensile strength and modulus decreases with the PTS content. In $X$-PIS the tensile strength and the modulus increase with the APTS content.

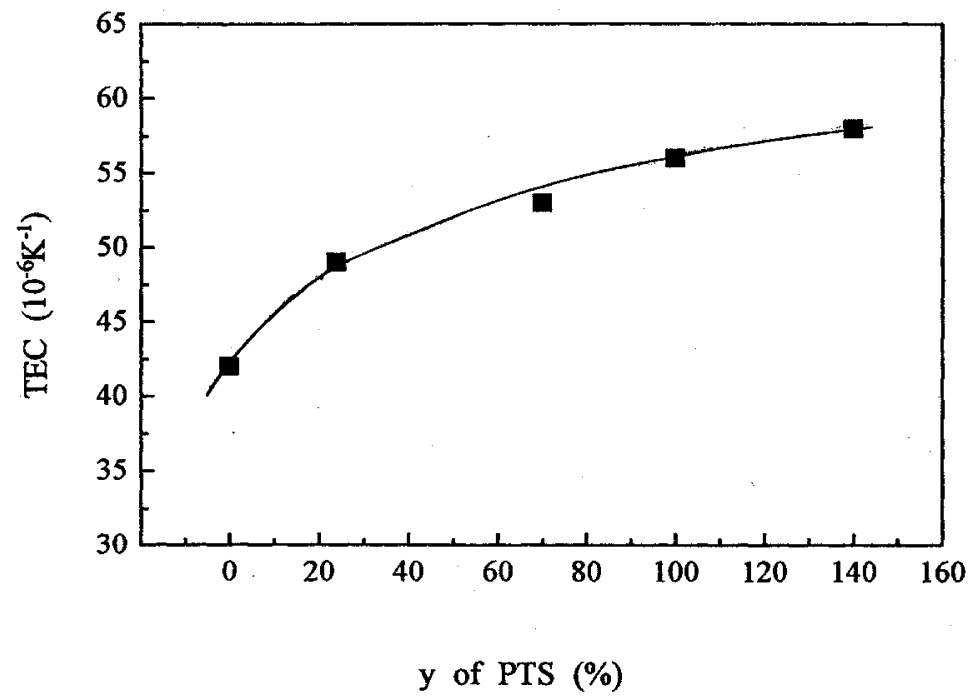

Fig. 6. Coefficient of thermal expansion below $T_{\mathrm{g}}\left(\alpha_{\mathrm{g}}\right.$, range $\left.30-220^{\circ} \mathrm{C}\right)$ of 5000-PIS- $y$-PTS hybrid films. 


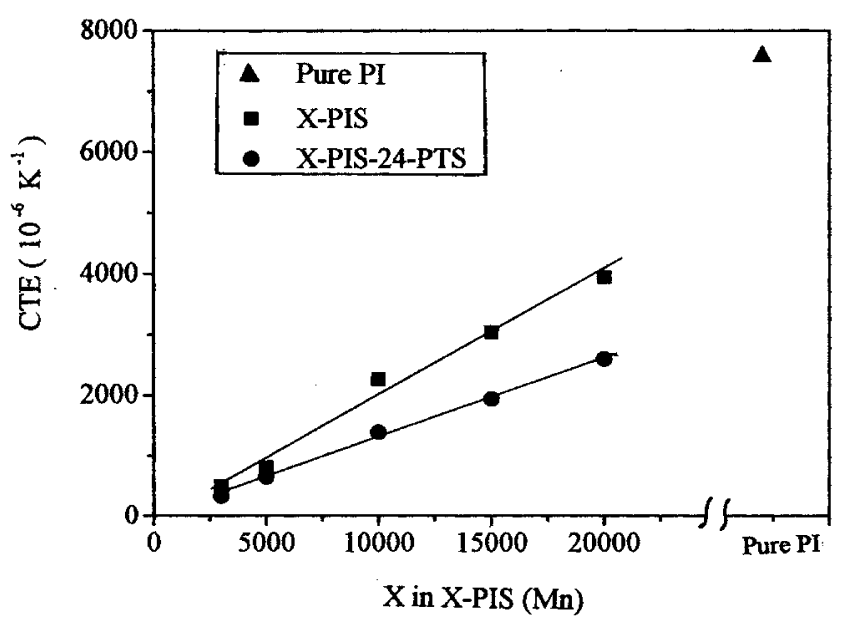

Fig. 7. Coefficient of thermal expansion above $T_{\mathrm{g}}\left(\alpha_{\mathrm{r}}\right.$, range $T_{\mathrm{g}}$ to $\left.T_{\mathrm{g}}+50^{\circ} \mathrm{C}\right)$ of pure PI and $X$-PIS, and $X$-PIS-24-PTS.

\section{Conclusions}

PI/PSSQ-like hybrid material has been successfully prepared by a self-catalyzed hydrolysis/condensation process. The synthesis is creative to avoid adding external catalyst or water, using only self-acid groups as catalysts and water from air. The PSSQ-like nanocomposite hybrid films have excellent transparency in visible light even under high content of PTS, and the PSSQ-like domain sizes depending on the composition are in the range 30-600 nm by both TEM and SEM observation. The PSSQ-like domains are fairly homogeneously dispersed in the films. The main reason may be due to the PI blocks chemically bonding with the APTS, which can bond with PTS to form PSSQ-like domains. Therefore, high homogeneity and high transparency in the hybrid films result. The PI/PSSQ-like hybrid films have higher onset decomposition temperature and char yield in TGA and higher $T_{\mathrm{g}}$ in DSC than the pure PI. In $X$-PIS films, the CTE decreases with the shorter PI block length in the hybrid films, which is attributed to increasing the $T_{\mathrm{g}}$ and cross-linking density of the network structure, resulting in increasing chain stiffness and decreasing CTE. Moreover, the $X$-PIS has lower CTE than pure polyimide. In the series of $X$-PIS- $y$-PTS films with a constant PI block length, the dielectric constant and water absorption decrease with PTS content. This may be due to the increase of free volume and the hydrophobicity of the hybrid films, which diminishes the moisture uptake. Higher PTS content can cause bigger PSSQ-like domain size leading to more free volume and a lower dielectric constant. The phenyl group on each PTS molecule may increase the hydrophobicity of the PSSQ-like domains. Therefore, the free volume is not occupied by more water molecules. The lowest dielectric constants of the nanocomposite in the series of 5000-PIS-140-PTS and 10000-PIS-100-PTS are 2.79 and 2.85 , respectively. In $X$-PIS films, the CTE $\left(\alpha_{\mathrm{g}}\right)$ decreases with the APTS. On increasing the PTS content, the CTE $\left(\alpha_{\mathrm{g}}\right)$ of $X$-PIS- $y$-PTS films slightly increases because free volume increase and $T_{\mathrm{g}}$ decreases with PTS content. Both factors lead to a higher CTE. However, the CTE $\left(\alpha_{\mathrm{g}}\right)$ above $T_{\mathrm{g}}$ of $X$-PIS-24-PTS decreases drastically compared with that of the $X$-PIS and pure PI.

\section{Acknowledgements}

The authors would like to express their appreciation to the National Science Council of the Republic of China and China Petroleum Company for financial support of this study under grant NSC 89-CPC-E-009-008. We would like to thank Mr Chin-Lung Hung for assistance with the scanning electron microscopy, Ms Su-Jen Chang for providing the dielectric measurement, Mr Yun-I Tien and Ms MeiLi Chang for assistance with the sample preparation and transmission electron microscopy.

\section{References}

[1] Ghosh MK, Mittal KL, editors. Polyimides: fundamentals and applications. New York: Marcel Dekker, 1996.

[2] Mittal KL. Polyimides: synthesis, characterization, and applications. New York: Plenum Press, 1984.

[3] Abadie JM, Sillion B, editors. Polyimids and other high-temperature polymers. New York: Elsevier, 1991.

[4] Wilson D, Stenzenberger HD, Hergenrother PM, editors. Polyimides. New York: Blackie, 1990.

[5] Tummala RR, Keyes RW, Grobman WD, Kapin S. In: Tummala R, Rymaszewski EJ, editors. Microelectronics packaging handbook. New York: Van Nostrand Reinhold, 1989 (chap. 9).

[6] Ukishima S, Iijima M, Sato M, Takahashi Y, Fukada E. Thin Solid Films 1997;308:475.

[7] Hougham G, Tesoro G, Shaw J. Macromolecules 1994;27:3462.

[8] Hougham G, Tesoro G, Viehbeck A. Macromolecules 1996;29:3453.

[9] Hougham G, Tesoro G, Viehbeck A, Chapple-Sokol JD. Macromolecules 1994;27:5964.

[10] Maruo YY, Andoh Y, Sasaki SJ. Vac Sci Technol A 1993;11:2590.

[11] Auman BC, Higley DP, Scherer Jr. KV, Mc Cord EF, Shaw Jr. WH. Polymer 1995;36:651.

[12] Wang S, Ahmad Z, Mark JE. Macromol Rep 1994;A31:411. 
[13] Wang S, Ahmad Z, Mark JE. Polym Bull 1993;31:323.

[14] Morikawa A, Iyoku Y, Kakimoto M, Imai Y. J Mater Chem 1992;2:679.

[15] Mascia L, Kioul A. Polymer 1995;36:3649.

[16] Srinivasan SA, Hedrick LJ, Miller RD, Di Pietro R. Polymer 1997;38:3129.

[17] Morikawa A, Iyoku Y, Kakimoto M, Imai Y. Polym J 1992;24:107.

[18] Ahmad Z, Sarwar MI, Mark JE. J Mater Chem 1997;7:259.

[19] Morikawa A, Yamaguchi H, Kakimoto M, Imai Y. Chem Mater 1994;6:913.

[20] Hedrick JL, Cha HJ, Miller RD, Yoon DY, Brown HR, Srinivasan S, Di Pietro R, Cook RF, Hummel JP, Klaus DP, Liniger EG, Simonyi EE. Macromolecules 1997;30:8512.

[21] Schrotter JC, Smaihi M, Guizard C. J Appl Polym Sci 1996;61:2137.

[22] Sysel P, Pulec R, Maryska M. Polym J 1997;7:607.

[23] Kioul A, Mascia L. J Non-Cryst Solids 1994;175:169.

[24] Wang S, Ahmad Z, Mark JE. Chem Mater 1994;6:943.
[25] Wen J, Wilkes GL. Chem Mater 1996;8:1667.

[26] Moo JH, Shin JW, Kim SY, Park JW. Langmuir 1996;12:4621.

[27] Nandi M, Conklin JA, Salvatijr L, Sen A. Chem Mater 1991;3:201.

[28] Goizet S, Schrotter JC, Smaihi M, Deratani A. New J Chem 1997;21:461.

[29] Mascia L, Kioul AJ. Mater Sci Lett 1994;13:641.

[30] Zhu ZK, Yang Y, Yin J, Qi ZN. J Appl Polym Sci 1999;73:2977.

[31] Beecroft LL, Johnen NA, Ober CK. Polym Adv Technol 1997;8:289.

[32] Iyoku Y, Kakimoto M, Imai Y. High Performance Polym 1994;6:43.

[33] Iyoku Y, Kakimoto M, Imai Y. High Performance Polym 1994;6:53.

[34] Iyoku Y, Kakimoto M, Imai Y. High Performance Polym 1994;6:95.

[35] Kang SJ, Kim DJ, Lee JH, Choi SK, Kin HK. Mol Cryst Liq Cryst 1996;280:277.

[36] Chen WC, Lin SC, Dai BT, Tsai MS. J Electrochem Soc 1999; 146:3004.

[37] Chen WC, Yen CT. J Polym Res 1999;6:197.

[38] Tsai MH, Whang WT. Submitted for publication. 